\title{
A CONSTRUÇÃO DO CONHECIMENTO NO MESTRADO EM SERVIÇO SOCIAL DA PUCRS ${ }^{*}$
}

\author{
Leonia Capaverde Bulla** \\ Jairo Melo Araujo** \\ Francisco Arselí Kern** \\ Idilia Fernandes**
}

SINTESE - Este estudo discute a possibilidade de o Serviço Social construir conhecimentos a partir da realidade em que atua. Conclui-se que, embora aplicando conhecimentos oriundos de outras ciências, o Serviço Social produz conhecimentos em sua área especifica. As dissertações de mestrado produzidas no período de 1981 a 1995 desvelam esses conhecimentos, sua relevância social, trazendo aportes para a solução dos problemas sociais da sociedade brasileira. Sua contribuição teórica situa-se, sobretudo, no campo das demandas e políticas sociais, embora tambèm seja significativa sua contribuição no aprofundamento das questões teórico-metodológicas do Serviço Social. Verificou-se, nos últimos anos, na produção estudada, a tendência de discussão dos novos paradigmas das ciências humanas e as novas exigências que serão impostas à profissão face às mudanças e avanços científico-tecnológicos do sécu$10 \mathrm{XXI}$.

\begin{abstract}
This study deals with the social science from the viewpoint of the possibility to construct knowledges based on the reality in which it acts. The experience confirms this hypotesis. In fact, the dissertations for the master's degree, produced in our university since 1981 until 1995, reveal such knowledges, their social importance, and contribute to solve social problems in our society. Theoritically this contribution mainly appears in the area of social and political demands, but also contributes to give a deeper basis for theoretical and metodological questions of social science. The dissertations show also the tendency to discuss the new paradigms of human sciences and the new demands which will exert influence on the profession, on account of the changes and the cientific as well as tecnological advancements in the next century.
\end{abstract}

\section{1 - Introdução: o problema de pesquisa e suas questões teóricas}

No quadro dos saberes estabelecidos, o Serviço Social tem sido considerado como disciplina profissional que, atuando no campo social, aplica conhecimentos produzidos em outras ciências. Nas últimas décadas, os profissionais da área têm

- O presente texto foi extraído do relatório de pesquisa "A construção de conhecimento em Serviço Social" desenvolvida na Faculdade de Serviço Social da PUCRS, de 1993 a 1996, tendo sido seu resumo apresentado na 48² Reunião Anual da SBPC, PUCSP, de 07 a 13 de julho de 1996.

* Faculdade de Serviço Social da PUCRS.

\begin{tabular}{|l|l|l|l|l|l|}
\hline VERTTAS & Porto Alegre & v. 41 & $\mathrm{n}^{2} 164$ & Dezembro 1996 & p. 715-727 \\
\hline
\end{tabular}


questionado os conhecimentos sobre os quais se fundamentam suas ações e as possibilidades de o Serviço Social produzir conhecimentos sobre a realidade em que atua. Passaram a colocar-se, como exigência fundamental, a tarefa de repensar sua teoria e sua ação, tentando desfazer as dicotomias teoria/prática, pensamento/ação, sujeito/objeto, produção/aplicação de conhecimentos.

A ciência tem evoluído de forma extraordinária, nos últimos tempos, invadindo todos os setores da sociedade, em busca de uma racionalidade cada vez maior de seus meios, suas técnicas e sua organização. Por outro lado, o trabalho científico tem se fragmentado, se pulverizado, entrando em especificidades tais que parece ser impossível uma visão de totalidade. A ameaça de destruição do homem e do planeta pelos próprios produtos do conhecimento científico tem levado os filósofos, cientistas e intelectuais em geral a se questionarem sobre as formas de utilização do saber, a dominação exercida pelos detentores da ciência e da teconologia e sobre a necessidade de uma ética ligada à ciência.

Os pensadores e filósofos da Escola de Frankfurt têm dado grande contribuição a essa discussão, questionando o poder ligado ao saber, a dominação exercida pelos detentores da ciência e da tecnologia, o aparato técnico de produção e destruição que mantém os países mais pobres subordinados às grandes potências.

Acompanhando estes questionamentos, foi se introduzindo no Serviço Social uma crítica dos conhecimentos sobre os quais se fundamentavam as suas práticas. O modelo de ação social que predominara nas primeiras décadas do Serviço Social brasileiro foi criticado, porque "não atuava sobre as causas" da questão social, atuando mais sobre os seus "efeitos". ${ }^{2}$ A partir de 1945, esse modelo, de origem franco-belga e de orientação filosófica e idealista passou por uma série de alterações, com os influxos da tecnologia científica, que foi sendo transplantada dos Estados Unidos para o Serviço Social brasileiro. Sob a influência do modelo funcionalista e cientificista norte-americano, a ação do Serviço Social se tripartia em Serviço Social de Casos, Grupo e Comunidade e se especializava em vários campos, de tal forma que já não parecia haver uma, mas várias profissões.

Nas últimas décadas, a nova geração de profissionais tem questionado radicalmente o referencial teórico e as metodologias tradicionais do Serviço Social. O movimento de reconceituação que surgiu no fim da década de sessenta, no interior do Serviço Social, pretendia que fossem superados tanto o idealismo como o cientificismo asséptico, considerado "gerador da indiferença aos fins e da inocência ideológica". ${ }^{3}$

Criticava a fragmentação da prática que setorializava a realidade e propunha uma visão da totalidade social. Com base nessa orientação, o Serviço Social passou a se colocar, como exigência fundamental, a tarefa de repensar a sua teoria e sua prática, de tentar desfazer as dicotomias teoria/prática, produção/aplicação, pensamento/ação, sujeito/objeto.

1 HABERMAS, Jurgen. Técnica e Ciência enquanto 'ideologia'. Pensadores. Textos escolhidos. 2. ed. São Paulo: 1983, p. 316-317.

2 JUNQUEIRA, Helena Juracy: "Quase duas décadas de reconceituação do Serviço Social: uma abordagem crítica. In: Serviço Social \& Sociedade, 4:1-38, 1980, p. 3.

3 KRUSE, Hermann. C. Filosofia do Século XX, p. 37. 
Em lugar de mero aplicador dos conhecimentos produzidos por outras disciplinas e em outras realidades, tentar-se-ia pensar sobre os objetos ou fenômenos com os quais se depara no exercício profissional, tentando participar do processo de produção do conhecimento, vistos sob uma perspectiva de totalidade social. ${ }^{4}$ Isso implicaria em visão dos fenônemos ligados entre o todo e as partes. Não se tratava apenas da elaboração de um saber explicativo e unificador, mas da construção de um conhecimento que contribuísse realmente para o processo de mudança e de transformação social.

Essa atividade teórico-prática tem desafiado os profissionais do Serviço Social nesses últimos anos. Os modelos tradicionais estavam prontos para a sua aplicação na prática cotidiana e para serem ensinados nos cursos de Serviço Social. Colocava-se à disposição dos interessados o saber acumulado sobre esses modelos, através de bibliografia especializada relativamente extensa, a maioria já traduzida para o Português, contando-se também com textos brasileiros e latino-americanos. 0 grande desafio tem sido a produção de conhecimentos específicos de Serviço Social a partir da práxis social, com base em referenciais teóricos alternativos e que deve levar em conta, não só as grandes tendências sociais da atualidade, mas também as novas aspirações e necessidades dos grupos culturais com os quais os assistentes sociais interagem. ${ }^{5}$

Como os assistentes sociais da região sul tem respondido a esses desafios de construção de novos conhecimentos? Iniciando uma linha de pesquisa que pretende buscar respostas a esta indagação, nos propusemos a investigar a produção de um grupo de profissionais, aqueles que concluíram o Curso de Mestrado em Serviço Social na PUCRS.

O Serviço Social foi institucionalizado no Rio Grande do Sul a partir da década de 40, no contexto do desenvolvimento capitalista, do agravamento das questões sociais e da implantação de medidas de política social pelo governo populista de Vargas. A Faculdade de Serviço Social da PUCRS, fundada em 1945, foi o centro pioneiro de formação de assistentes sociais do Estado e da Região Sul.

O Curso de Mestrado de Serviço Social da PUCRS iniciou suas atividades em 1977 e, na elaboração de sua proposta curricular, houve uma preocupação básica na articulação entre ensino e pesquisa. Pretendia-se, desse modo, formar profissionais pesquisadores que contribuíssem para a organização e o avanço do saber em Serviço Social.

Nesses dezenove anos de existência, o Curso de Mestrado funcionou como um centro regional de formação e aperfeiçoamento de docentes e de pesquisadores. Tem atendido, principalmente, a demanda de universidades e instituições educacionais e sociais da Região Sul, por ser o único curso de mestrado nessa Região, acolhendo, também, demandas de outros estados brasileiros e de países do Cone Sul. Em 1981 foram produzidas as primeiras dissertações neste mestrado, perfazendo até 1995 um total de 75 dissertações, que são objeto desta pesquisa.

4 Ver discussões sobre a 'totalidade' numa concepção dialética em KOSIK, Karel. 3. ed. Rio de Janeiro: Paz e Terra, 1976.

5 BULLA, Leonia Capaverde. Serviço Social, Educação e Práxis: tendências teóricas e metodológicas. Porto Alegre: FACED/UFRGS (Tese de Doutorado), 1992. 


\section{2 - Objetivos do estudo}

- Analisar as dissertações de mestrado em Serviço Social da PUCRS, como uma das formas de desvelar os conhecimentos teóricos e metodológicos que têm sido produzidos no Serviço Social.

- Estudar o conhecimento construído, relacionando-o historicamente com a produção de conhecimento em Serviço Social, em nivel nacional e com o contexto social, econômico, político e ideológico brasileiro e gaúcho.

- Verificar se o saber construído no Curso traz contribuições para a solução dos grandes problemas sociais de nossa realidade, em união com os esforços e tentativas de mudanças e transformações sociais da sociedade brasileira.

- Oferecer subsídios para o processo de planejamento curricular dos cursos de Graduação e de Pós Graduação em Serviço Social da PUCRS.

\section{3 - A especificidade do Serviço Social na construção do seu objeto}

O Serviço Social desenvolve a construção de seu objeto, sua relação com este objeto, de uma forma significativamente peculiar. $\mathrm{O}$ assistente social defronta-se, em seu cotidiano profissional, com questões práticas e humanas, para as quais busca soluções. Nesse sentido, é um profissional que deve conhecer profundamente 0 objeto de sua ação, para poder dar uma resposta eficiente e de qualidade aos problemas propostos.

Sendo assim, a peculiaridade do Serviço Social situa-se na construção do seu objeto de estudo, que está sempre em relação direta com necessidades emergentes, requeridas pela realidade social na qual está inserido.

Em qualquer área do saber, a produção de conhecimento se faz a partir da realidade, mas no Serviço Social a questão se coloca de uma forma mais singular. No Serviço Social, há um mundo relacional, que é o cenário onde se debatem inúmeras singularidades em um contexto complexo e contraditório. São pessoas das diferentes classes sociais com problemas mais diversificados, tanto de natureza emocional, como sócio-econômica e que muitas vezes se configuram como exclusão social.

A contemporaneidade do conhecimento social é vista como uma totalidade complexa que inclui diversidades e heterogeneidades do saber, causando tensões entre os paradigmas. O conhecimento no Serviço Social é complexo. Não há uma unicidade no Serviço Social. Diferentes correntes filosóficas do pensamento permeiam as abordagens teórico-metodológicas no decorrer das décadas. A vertente teórica que predomina em um determinado momento histórico convive com outros paradigmas.

Atualmente a maioria dos teóricos do Serviço Social brasileiro, reconhecidos pela categoria, vinculam-se ao pensamento marxista. Isso não significa que a maioria da categoria profissional, que está imersa no cotidiano da práxis, tenha optado por essa abordagem teórico-metodológica. A vinculação a uma prática concreta, humana relacional, é o que particulariza e especifica o conhecimento produzido pelo assistente social, sendo a intervenção profissional no social o ponto que nos diferencia dos demais. É preciso saber e saber fazer com competência, dando respostas aos desafios do social. 


\section{4 - Procedimentos metodológicos}

Foram analisadas todas as dissertações de mestrado em Serviço Social da PUCRS, em número de 75, desenvolvidas no período de 1981 a 1995, utilizando-se procedimentos de análise de conteúdo, condizentes com os objetivos e questões norteadoras da pesquisa.

Inicialmente, seguimos alguns procedimentos da orientação de Bardin, ${ }^{6}$ quanto à divisão do processo de análise em três fases. Num primeiro momento, elaboramos o instrumental para efetivar a coleta de informações de acordo com a proposição do estudo. Este instrumental, uma ficha preenchida para cada dissertação, compõe-se de um roteiro com questões abertas, assim constituído:

1. Identificação

\subsection{Autor}

1.2 Título

1.3 Caracterização

$1.4 \mathrm{Local}$

1.5 Data

1.6 Objetivo

2. Tema

2.1 Relevância do tema

2.1.1 Contemporânea

2.1.2 Operativa

2.1.3 Humana

3. Os valores sociais ou individuais explícitos ou implícitos no trabalho (pólo axiológico)

4. Processo de construção do conhecimento (pólo epistemológico)

4.1 A construção do objeto de estudo

4.2 A relação estabelecida entre sujeito que conhece e objeto que se torna conhecido

5. Os processos discursivos ou lógicos que orientam a pesquisa (pólo epistemológico)

6. Correntes teóricas que predominam (pólo teórico)

7. Orientação metodológica do estudo (pólo teórico)

7.1 Empírico-Analítica

7.2 Fenomenológico-Hermenêutica

7.3 Dialético-Crítica

7.4 Outras

8. Instrumentos e técnicas utilizadas (pólo morfológico e técnico)

8.1 São explicitados os instrumentos e técnicas mantendo coerência entre si?

6 BARDIN, Laurence. Análise de conteúdo. Lisboa: Edições 70, 1977. 
8.2 Os instrumentos e técnicas utilizadas correspondem à orientação metodológica do estudo?

\section{Parecer pessoal sobre a dissertação}

Num segundo momento, iniciamos a leitura integral de cada dissertação, o nosso objeto de estudo, procurando responder às questões propostas, preenchendo uma ficha para cada dissertação. Num terceiro momento, foi realizada uma descrição analítica do material, desvelando-se algumas categorias, como a relevância do tema, a construção do objeto de estudo e a orientação metodológica. Nesta fase, tornou-se possivel agrupar algumas informações de acordo com a eleição das categorias.

Por fim, realizamos a interpretação à luz do referencial teórico, resultado da reflexão sobre os conteúdos manifestos e latentes. Procuramos compreender os significados das comunicações, dos discursos dos assistentes sociais, suas intenções, as tendências de seu pensamento.

A leitura hermenêutica dos documentos foi associada a uma análise histórica crítica com base no contexto social, político, econômico e cultural. Essa fase ainda está em andamento. Os resultados e considerações apresentados neste trabalho ainda são preliminares.

\section{5 - Resultados preliminares: a produção do Curso de Mestrado em Serviço Social}

\begin{tabular}{l|cccc}
\hline Dissertações/Período & 1981-1985 & $1986-1990$ & $1991-1995$ & Total \\
\hline Demandas e Políticas Sociais & 09 & 14 & 17 & 40 \\
Metodologias em Serviço Social & - & 03 & 14 & 17 \\
Ensino em Serviço Social & 05 & 05 & 04 & 14 \\
Construção de Conhecimento & - & 01 & 03 & 04 \\
Total & 14 & $\mathbf{2 3}$ & $\mathbf{3 8}$ & $\mathbf{7 5}$ \\
\hline
\end{tabular}

Constatou-se que, ao longo da história do Mestrado em Serviço Social da PUCRS o conhecimento produzido se concentra nas seguintes áreas de saber: Demandas e Políticas Sociais, com 40 dissertações defendidas. Metodologias do Serviço social com 17 dissertações; Ensino em Serviço Social, com 14 dissertações; e Construção do Conhecimento, com 4 dissertações.

\section{1 - Demandas e Politicas Sociais}

\begin{tabular}{l|cccc}
\hline Dissertações/Período & 1981-1985 & $1986-1990$ & $1991-1995$ & Total \\
\hline Demandas e Políticas Sociais & $\mathbf{0 9}$ & $\mathbf{1 4}$ & $\mathbf{1 7}$ & $\mathbf{4 0}$ \\
\hline
\end{tabular}

A produção em Demandas e Políticas Sociais, foi constante durante a história do Mestrado, apresentando um crescimento de 9, para 14 e 17 dissertações. Estão 
representadas nesses trabalhos as várias áreas em que o Serviço Social intervém, atendendo demandas, desenvolvendo ou propondo políticas setoriais, conforme as seguintes sub- categorias :

- exclusão social e assistência social;

- política da criança e adolescente;

- política do idoso;

- violência contra a mulher;

- família de baixa renda em vilas de sub habitação;

- as práticas de educação popular;

- deficiência física e mental;

- políticas de saúde e trabalho;

- o processo de municipalização da saúde;

- a prática institucional;

- administração institucional e novas práticas de gestão.

Caracteriza-se como demanda a reivindicação pelo suprimento de uma necessidade que o usuário apresenta a uma instituição. Como objetivos desta linha de pesquisa, definiu-se: conhecer e analisar a realidade social e institucional buscando dimensionar o tipo de problemática apresentada pela população, suas características, hábitos, costumes, procedências e estratégias de sobrevivência, estando atento às demandas sociais emergentes. Analisar de forma crítica as Políticas Sociais que regem procedimentos profissionais, que se propõem a responder às demandas dos usuários e à indicação das realidades sociais.

As demandas políticas e sociais são constituídas por temas que surgem do dia-a-dia profissional do assistente social, de seus usuários, das instituições. Os assuntos sobre os quais se debate no excercício profissional e a realidade social trazem subsídios para a construção do objeto de estudo.

As dissertações de mestrado em Serviço Social da PUCRS demonstram que os profissionais do social buscam aprofundar os temas com os quais se deparam e investigam para dar sua contribuição ao conhecimento da realidade, na qual se articulam os processos sociais. A proximidade entre 0 assistente social e 0 objeto de sua ação propicia-lhe condições de indicar aos profissionais das demais áreas alguns caminhos em relação ao contexto conjuntural e também sobre o sujeito desse contexto.

\section{2 - Metodologias em Serviço Social}

\begin{tabular}{l|cccc}
\hline Dissertações/Período & 1981-1985 & 1986-1990 & 1991-1995 & Total \\
\hline Metodologias em Serviço Social & - & $\mathbf{0 3}$ & $\mathbf{1 4}$ & $\mathbf{1 7}$ \\
\hline
\end{tabular}

As dissertações em Metodologias em Serviço Social começaram a ser elaboradas em 1986, apresentando maior incidência no período de 91 a 95. Voltaram-se para as construções teórico-metodológicas no desenvolvimento da ação profissional, em várias áreas de atuação, conforme as seguintes sub-categorias:

- ação profissional com usuários em âmbito institucional;

- movimentos sociais e comunitários; 
- abordagem de Serviço Social alternativo;

- planejamento estratégico e democratização;

- abordagem interdisciplinar.

As dissertações em Metodologias do Serviço Social discutem, questionam e apresentam propostas teórico-metodológicas. Demonstram preocupação com o desempenho profissional, realizam exercícios de construções metodológicas que se caracterizam como experiências criativas e competentes, perpassadas pela vigilância epistemológica.

Esses exercícios iniciam-se em sala de aula, quando os mestrandos estudam, na fonte, autores clássicos do Serviço Social que elaboraram propostas metodológicas. Esse estudo caracteriza-se pelo desmontar com o intuito de perceber os elementos que integram a composição e articulação das metodologias. A seguir, os alunos exercitam a construção de propostas metodológicas, com base em referenciais teórico-epistemológicos discutidos por autores contemporâneos.

A competência e qualificação profissional vêm evoluindo no compasso das transformações sociais, na dimensão da capacitação teórico-prática do assistente social, com a experiência de construções de exercícios em Metodologias de Serviço Social. O desafio de construir, criticar e reconstruir se configura num fazer metodológico, expressado-se em múltiplas formas, atento aos pólos axiológicos, morfológicos, epistemológicos e teóricos. Esse processo construtivo tem implícita a preocupação com a produção de conhecimentos, que remete aos docentes e discentes a possibilidade e a experiência em dimensionar a realidade e de intervir na mesma, numa perspectiva de pluralidade, com vistas ao saber e ao saber fazer.

Como objetivo dessa linha, definiu-se: desenvolver um estudo epistemológico das tendências metodológicas do Serviço Social e as influências das correntes do pensamento contemporâneo nas estratégias de ação do Serviço Social, possibilitando a compreensão dos elementos constitutivos das metodologias em Serviço Social e as possibilidades de construção de novos modelos.

As tendências da construção de conhecimento em Metodologias em Serviço Social se voltam para uma perspectiva de elaboração de ensaios metodológicos que venham a contribuir com a profissão no que compreende a intervenção planejada em termos teóricos e metodológicos. No que diz respeito às construções metodológicas, permeia a relevância das construções, com significativas contribuições ao Serviço Social. Trata-se de um projeto político da profissão enquanto suporte e possibilidade de leitura da realidade, estabelecendo uma relação entre teoria e prática de forma organizada e interventiva.

As Metodologias em Serviço Social possibilitam demonstrar a multidimensão da realidade. As temáticas abordadas associam-se à busca de melhorias na intervenção da profissão, propiciando viabilidade, competência, reflexão entre teoria e prática. Esta postura compreende diálogo, debate num caráter dinâmico, operativo e singular com vistas à possibilidade de ação conjunta de profissionais na atenção globalizada a questões coletivas e individuais. Supera-se assim a intervenção fragmentada, contribuindo sobremaneira para que ocorram mudanças no agir profissional com fundamentação teórica, epistemológica e metodológica. 


\section{3 - Ensino em Serviço Social}

\begin{tabular}{l|cccc}
\hline Dissertações/Período & 1981-1985 & 1986-1990 & 1991-1995 & Total \\
\hline Ensino em Serviço Social & $\mathbf{0 5}$ & $\mathbf{0 5}$ & $\mathbf{0 4}$ & $\mathbf{1 4}$ \\
\hline
\end{tabular}

A linha de pesquisa de Ensino em Serviço Social tem apresentado uma produção constante, 5 , 5 e 4 dissertações, perfazendo um total de 14 dissertações, classificadas nas seguintes sub-categorias:

- a formação e qualificação profissional;

- ensino e avaliação do processo de aprendizagem;

- supervisão no processo de formação profissional;

- educação, consciência e transformação.

De modo geral, percebe-se que o ensino do Serviço Social encontrou novos horizontes a partir das concepções sobre o ensino e formação profissional assumidas pelo corpo docente e discente da Faculdade, em sintonia com as várias entidades da categoria profissional, tais como: Associação Brasileira de Ensino de Serviço Social, Centro de Documentação e Pesquisa em Políticas e Serviço Social, Conselho Regional e Conselho Federal de Serviço Social. À medida que esta concepção vai se efetivando, define-se também o projeto de formação profissional que se efetua no decorrer de um processo, em que a categoria se mobiliza em busca de sua identidade profissional.

Como objetivo desta linha de pesquisa, definiu-se: conhecer as interfaces da formação profissional, o estudo do plano curricular dos cursos de Serviço Social: filosofia, objetivos educacionais, estratégias de ensino e instrumentos de avaliação, estudando as propostas pedagógicas e os referenciais teóricos norteadores.

A Faculdade de Serviço Social da PUCRS, no seu processo de formação, segue princípios norteadores com relação ao ensino que se identificam como a preocupação com a formação do aluno (saber e saber ser), o espaço de exercício da formação e o ensino das concepções sobre metodologias e instrumentalidade, o que leva o aluno ao aprendizado do como fazer, (saber fazer).

Assim, a temática do ensino em Serviço Social torna-se significativa, enquanto a entendermos como reflexão em conjunto com o corpo docente e discente, com 0 objetivo de conhecer, mas dando ênfase à dimensão política do ensino e da prática profissional. No ensino, está implícita a concepção de formação profissional, partindo-se do pressuposto que a profissão se faz permanentemente num processo de sempre estarmos atentos à conjuntura/estrutura na qual a mesma está presente.

5.4 - Construção de Conhecimento

\begin{tabular}{l|cccc}
\hline Dissertações/Período & 1981-1985 & 1986-1990 & 1991-1995 & Total \\
\hline Construção de Conhecimento & - & 01 & 03 & 04 \\
\hline
\end{tabular}

Os trabalhos desenvolvidos nesta linha de pesquisa objetivam o exercício e análise da Construção do Conhecimento em Serviço Social, desvelando o contexto 
das discussões específicas da profissão. Assim, estes estudos abordaram, entre outros, os seguintes temas:

- correntes de pensamentos filosófico-epistemológicos presentes na formação e na prática do Serviço Social;

- concep̧̧ões e conceitos do social no discurso do Serviço Social;

- a proposição de novos paradigmas para o Serviço Social.

Alguns pressupostos fundamentam a reflexão quanto ao conhecimento de determinado fenômeno que se queira estudar. $\mathrm{O}$ homem não age diretamente sobre as coisas. Sempre há um intermediário, um instrumento entre ele e seus atos. Conhecer é a relação que se estabelece entre sujeito que conhece e o objeto que se torna conhecido. Ao nível dessa construção, a gnoseologia adquire posições contraditórias. Isto quer dizer que a uma filosofia materialista corresponderá um conhecimento de ordem materialista diferenciada da gnoseologia idealista.

Os primeiros princípios são proposições que ficam evidentes por si mesmas. Os princípios são vistos como pressupostos no ato de conhecer. Cada forma de conhecer possui de antemão pressupostos que possibilitam o desencadeamento da temática do conhecimento.

$\mathrm{O}$ ato de conhecer não se apresenta uniforme e único. A sua dimensão é múltipla e variada. Conhecer é adquirir entendimento sobre o objeto de estudo. $\mathrm{O}$ entendimento é construído quando o sujeito cognoscente penetra no interior do objeto através do conhecimento e aproxima-se da essência.

Conhecer passa a ter uma conotação superior, além de apenas ver, mas estende-se a uma dimensão de participação do sujeito na existência do ser conhecido. Assim, o objeto conhecido torna-se parte do mundo do sujeito cognoscente.

Os modos do ato de conhecer adquirem diferentes conotações em intensidade e profundidade dependendo da forma como o objeto conhecido é apreendido. Os diferentes modos podem ser classificados como

- conhecer propriamente dito - é caracterizado pelo contato direto entre sujeito e objeto. Neste contato, evidencia-se um certo primarismo e rusticidade do material colhido. O sujeito cognoscente poderá trabalhar este material através de meditação, reflexão e transformar o conhecer em saber;

- o saber "é um modo mais complexo de conhecimento". ${ }^{7}$ É entendido na diferença existente entre conhecer o objeto e saber sobre o objeto. O saber é marcado, não através do contato direto, porque este tipo de aproximação acontece no conhecer. O saber representa uma posse final e definitiva do objeto.

Em termos epistemológicos, o objetivo desta linha de pesquisa é estudar o conhecimento construído pelo Serviço Social no Rio Grande do Sul, indicando tendências da profissão, bem como verificar se o saber construído tem trazido contribuições para a solução dos grandes problemas sociais de nossa realidade. Objetiva-se exercitar a construção de conhecimento, desvelando-se o contexto de dilemas próprios da discussão atual do Serviço Social em um cenário de desafios.

7 GIRARDI, Leopoldo Justino \& QUADROS, Odone José. Filosofia. Série Universitária. Porto Alegre: Emma, 1993, p. 81. 
Ao se tratar de construir conhecimento acerca do Serviço Social, está presente nesse processo o arsenal de instrumentalização que contribui para essa construção. Para que determinado objeto se dê por conhecido com o uso e aplicação de instrumentais técnicos qualificados, a investigação se volta para os sentidos do todo, sejam estes externos ou internos.

Considerando a multiplicidade de visões teóricas e filosóficas que embasam a prática profissional, a construção de conhecimento passa a corresponder ao referencial teórico adotado, seja por uma linha que se caracteriza, a priori, materialista, ou por uma tendência mais espiritualista ou idealista. O Serviço Social, ao construir conhecimento, está voltado para a realidade em que atua. Como isto se dá na prática? Antes de tudo, Serviço Social é uma área de conhecimento sobre a qual a profissão se estrutura. Como disciplina profissional, busca a constituição de um conhecer específico e qualificado no que diz respeito ao objeto de intervenção ao homem como sujeito da ação e à realidade social como um todo.

O conhecer no Serviço Social, como foi enfatizado anteriomente, não tem em geral o objetivo de apenas desvelar o objeto e se apropriar do mesmo. Busca-se 0 conhecimento com objetivo de contribuir para a solução dos grandes problemas sociais enfrentados pela nossa socieddade.

\section{6 - Considerações finais}

Embora aplicando conhecimentos oriundos de outras ciências, o Serviço Social produz conhecimentos em sua área específica. As dissertações de mestrado desvelam esses conhecimentos, sua relevância social, trazendo aportes para a solução dos problemas sociais. Sua contribuição teórica situa-se, sobretudo, no campo das demandas e políticas sociais, embora também sejam significativos os estudos para aprofundamento das questões teórico-metodológicas do Serviço Social. Verificouse, nos últimos anos, na produção estudada, a tendência à discussão dos novos paradigmas das ciências humanas e das novas exigências que serão impostas à profissão, face às mudanças e avanços científico-tecnológicos do século XXI.

Com a perspectiva de construir o corpo teórico do Serviço Social, as categorias pessoa, singular, coletivo e social, na dimensão de construção de conhecimento, são vistas com prioridade. A forma de trabalhar essas categorias, a partir das múltiplas visões teóricas, caracteriza a postura do pluralismo. Um dos elininentos que se tem em comum e que perpassa todos os estudos realizados é justamente 0 elemento da livre opção do pesquisador profissional por um referencial teórico, que corresponda as suas concepções e aos objetivos do estudo.

Dessa postura decorre o compromisso profissional frente às demandas decorrentes na sociedade atual. Esse compromisso se firma a partir da concepção de universidade como instituição que com propriedade produz o social e as dimensões da socialização đos conhecimentos construídos. Será que as universidades de modo geral podem ser consideradas instâncias produtoras de conhecimentos? De acordo com Demo ${ }^{8}$ "nossas escolas e universidades não são contemporâneas, por-

8 DEMO, Pedro. Pesquisa e construção de conhecimento. Rio de Janeiro: Tempo Brasileiro, 1994, p. 15. 
que sequer se desempenham a contento como transmissoras e socializadoras do conhecimento".

Se produzimos na universidade, buscamos a verdade que é desenvolvida a partir do conhecimento e das nossas habilidades. O caminho que nos aproxima da verdade é indicado pela pesquisa que, por sua vez, busca a universalidade, a totalidade e a globalidade. A pesquisa que produz conhecimento e que atribui relevância à pessoa, ao singular, ao coletivo e ao social, assume compromissos, tais como:

a) socializar o saber produzido no diálogo com outras áreas de conhecimento, como uma forma de retribuição à sociedade que arca com o ônus de nossas pesquisas;

b) o compromisso com o mundo humano e social, em toda sua dinamicidade que, no contexto de hoje, final de milênio, é perpassado por crises profundas: do pensamento, com os questionamentos dos paradigmas; do mercado com a globalização da economia; do Estado, com as reformas e desmonte das políticas públicas de assistência e da sociedade, que se vê envolta pela violência e pela descrença nos seus representantes;

c) o compromisso com a ética social que se expressa nos procedimentos investigativos, que se estende aos sujeitos envolvidos no processo de pesquisa, que são partícipes de nossos estudos que visam construir conhecimentos;

d) o compromisso com a ciência, descortinando novos horizontes para o desenvolvimento humano e social.

O compromisso profissional do assistente social compreende exigência de saber, habilidades, competência e qualificação. Tendo presente a visão de globalidade, o pesquisador planeja de forma estratégica na ação profissional. Na execução, deve ter presente também a visão de singularidade do sujeito e do objeto de estudo.

O perfil do assistente social pesquisador tem como referência a sua formação profissional. Se assim for considerado, algumas características demarcam sua qualificação como pesquisador: o compromisso com a formação acadêmica, o conhecimento das políticas sociais, embasamento teórico-metodológico, postura de acordo com uma pedagogia que visa a transformação social.

Nessa perspectiva, define-se a dimensão política da prática profissional. Esta dimensão, de acordo com Martinelli, ${ }^{9}$ pressupõe uma direção ética que descortina um caminho a ser seguido. A prática não pode ser considerada pronta e acabada, mas esta se estabelece num processo de construção, em que a ética também se expressa no respeito aos sujeitos partícipes. Pressupõe uma construção coletiva sob a responsabilidade do profissional e dos sujeitos, não considerando as instituições como sistemas fechados. É a construção da prática por sujeitos e com sujeitos.

A dimensão política da prática exige também competência técnica, que se configura em transformar a realidade a partir da intersubjetividade, considerando a dimensão ético-política. Isto supõe que o profissional pesquisador desenvolva uma

9 Esta temática foi abordada pela prof. Maria Lúcia Martinelli em curso ministrado sobre "O debate contemporâneo do Serviço Social: rupturas e continuidades" no Curso de Mestrado em Serviço Social da PUCRS, no período de 27 a 29 de junho de 1995. 
prática integrada no âmbito institucional, que os conhecimentos e informações sejam socializados e que estabeleça o diálogo com outras áreas de conhecimento.

A direção ética, a construção coletiva e a competência técnica são básicas e, com esses elementos, o Serviço Social caracteriza com propriedade a dimensão política de sua prática, independente da corrente teórica ou filosófica que a fundamente. No trabalho em pesquisa, em instituições, assumir com responsabilidade a prática é pensá-la na direção que ela toma junto à sociedade, através de uma operacionalização do projeto político de ambas as partes, ou seja, do profissional e da instituição. A proposta, construída por sujeitos e com sujeitos, deve servir de orientação para o profissional que atua numa perspectiva de transformação social.

\section{Bibliografia}

ABESS. Associação Brasileira de Ensino em Serviço Social. A produçăo de conhecimento e o Serviço Social. Cadernos ABESS, n. 5. São Paulo: Cortez, 1992.

- Produção científica e formação profissional. Caderno ABESS, n. 6. São Paulo: Cortez, 1993.

BARDIN, Laurence. Análise de conteúdo. Lisboa: Edições 70, 1977.

BATISTA, Miriam Veras. Questōes que se colocam para a investigação da prática profissional. III Encontro Nacional de pesquisadores em Serviço Social. São Paulo: ABESS/CEDEPSS, 1993.

BORNHEIM, Gerd A. Dialética: Teoria e práxis. 2. ed. Porto Alegre: Globo, 1983.

BULLA, Leonia Capaverde. Serviço Social, Educação e Práxis: tendências teóricas e metodológicas. Porto Alegre: FACED/UFRGS (Tese de Doutorado), 1992.

CHATELET, François. História da filosofia. Rio de Janeiro: Zahar, 1981.

CORETH, Emerich. Questöes fundamentais da Hermenêutica. São Paulo: Editora Pedagógica Universitária/Universidade de São Paulo, 1973.

DEMO, Pedro. Pesquisa e construção de conhecimento. Rio de Janeiro: Tempo Brasileiro, 1994.

FALEIROS, Vicente de Paula. Metodologia e ideologia do trabalho social. São Paulo: Cortez, 1985.

GIRARDI, Leopoldo Justino., QUADROS, Odone José. Filosofia. Série Universitária. Porto Alegre: Emma, 1993.

GOLDMANN, Lucien. Dialética e cultura. 2. ed. Rio de Janeiro: Paz e Terra, 1979.

- Epistemologia e filosofia política. Lisboa: Presença, 1984.

HABERMAS, Jurgen. Técnica e Ciência enquanto ideologia. 2. ed. Pensadores. Textos escolhidos. São Paulo: Abril Cultural, 1983.

—_ Dialética e Hermenêutica. Porto Alegre: L\&PM, 1987.

JUNQUEIRA, Helena Juracy. Quase duas décadas de reconceituação do Serviço Social: uma abordagem crítica. In: Serviço Social \& Sociedade, 4:1-38, São Paulo: Cortez, 1980.

KOSIK, Karel. Dialética do Concreto. 3. ed. Rio de Janeiro: Paz e Terra, 1976.

KRUSE, Hermann. C. Filosofia do Século XX. Buenos Aires: Ecro, 1970.

LEFEBVRE, Henri. Lógica formal e lógica dialética. Rio de Janeiro: Civilização Brasileira, 1975.

MARTINELI, Maria Lúcia. O debate contemporâneo do Serviço Social: rupturas e continuidades. Curso ministrado no Mestrado em Serviço Social da PUCRS. Porto Alegre, 1995.

- Serviço Social: Identidade e alienação. São Paulo: Cortez, 1989.

PEREIRA, Leda C.R., CASTILLO, Lúcia, G. (Orgs.). Exercícios de construção teórico-metodógica do Serviço Social. Porto Alegre: EDIPUCRS, 1995. 